\title{
Constructividad y Razón narrativa: bases para un operar en terapia narrativa
}

\author{
Constructiveness and Narrative Reason: basis for \\ working in narrative therapy
}

Ana Maria Zlacheusky Ojeda

\section{Resumen}

El presente artículo muestra cómo el concepto de "narrativa" y el de constructivismo o constructividad han llevado a equívocos. Ello se liga con las dos tradiciones que han coexistido en el pensamiento psicológico. La cientificista, por un lado, y la fenomenología hermenéutica, por otro, teniendo cada postura una diferente manera de entender "lo humano"; por tanto, de comprender lo narrativo. La constructividad como postura epistemológica se liga al pensamiento de Maturana y Varela, acentuando las características del observador que está a la base de esta comprensión. Se termina el artículo proponiendo la razón narrativa, versus la razón lógica, como proceso que permitiría entender lo narrativo en la postura fenomenológica hermenéutica.

Palabras clave: constructivismo o constructividad, fenomenología hermenéutica, narrativa, razón narrativa.

\section{Abstract}

This article shows how the concepts of "narrative" and constructiveness or constructivism have been ambiguous and have led to misunderstandings. This is linked with two traditions that have coexisted in psychological thinking: psychology as a science, on one hand, and hermeneutic phenomenology, on the other. Each stance has a different understanding of "the human", and therefore of what narrative is. Constructiveness as an epistemological stance is linked to Maturana and Varela's theories, and it emphasizes the cha-

1 Escuela de Psicología de la Universidad Mayor, Santiago de Chile. E-mail: ana.zlachevsky@umayor.cl 
racteristics of the observer that bring forth what he comprehends. This article ends proposing narrative reason, versus logical reason, as a process that would allow to understand narrative in the hermeneutic phenomenological approach.

Key words: constructivism or constructiveness, hermeneutic phenomenology, narrative, narrative reason.

En el curso de la historia de la psicología se han sucedido diferentes formas de comprender al hombre, lo que ha llevado a "la creación de diferentes psicotecnologías" (Molinari, 2003, p. 3) o técnicas psicoterapéuticas. Indudablemente, el modelo sistémico narrativo es un modelo más, entre otros, pero es uno que ha estado invadiendo la forma de entender la psicoterapia en distintos países y escuelas docentes universitarias. No obstante, el concepto "narrativa" lleva a equívocos, y pienso que es necesario detenerse a reflexionar sobre ello. Este artículo no pretende ser una revisión exhaustiva del concepto de narrativa, sino solo una invitación a deliberar sobre el tema.

En psicoterapia, el terapeuta no anda en busca de verdades, sino que trata de escuchar el relato de un paciente o un sistema consultante, siguiendo la historia particular que le trae o traen a sesión, en el contexto de la o las biografías de cada uno. Muchas veces se detiene en hechos concretos, no para ver si son o no verdaderos, sino para lograr entender las acciones específicas que se desprenden de lo que le está o están relatando. En este punto parece interesante considerar el planteamiento de Bruner (1998) quien describió dos tipos de pensamiento: el pensamiento narrativo y el pensamiento paradigmático. Se está refiriendo a un modo del pensamiento que no debe confundirse con las psicoterapias narrativas. Dice Bruner: "hay dos modalidades de funcionamiento cognitivo, dos modalidades de pensamiento, y cada una de ellas brinda modos característicos de ordenar la experiencia, de construir la realidad" (p. 23). A una de las modalidades la llama paradigmática o lógico-cientifica, y a la otra, narrativa. Ambas son complementarias, pero, irreductibles una a la otra. Difieren fundamentalmente en sus procesos de verificación y en aquello de lo que 
intentan convencer. Los argumentos, propios del pensamiento paradigmático, "convencen de su verdad" (p. 23); los relatos, propios del pensamiento narrativo, aluden a "su semejanza con la vida" (p. 23).

La modalidad paradigmática da como resultado teorías sólidas, pruebas lógicas, argumentaciones firmes, y lleva a descubrimientos empíricos guiados por hipótesis razonadas. Trata de trascender lo particular, buscando niveles de abstracción cada vez más altos, rechazando todo aquello en lo que intervengan los sentimientos o las explicaciones particulares.

La modalidad narrativa, propia de la psicoterapia, por el contrario, se centra en las particularidades para poder llegar a entender cómo las personas se viven la vida (Zlachevsky, 2003). Produce buenos relatos, se ocupa de las acciones e intenciones humanas y de las vicisitudes que ocurren en el transcurso de una existencia. Sitúa los acontecimientos y las experiencias en el tiempo y en el espacio. Los relatos no tienen, como el pensamiento paradigmático, el requisito de verificabilidad, sino de verosimilitud en el contexto de una vida particular. Por ello el terapeuta tiene que ser capaz de reconocer la verosimilitud de lo narrado por el paciente, en el contexto de su biografía. El terapeuta que se centra en la biografía lo hace como lo haría un historiador, que contextualiza un acontecimiento en la época histórica del suceso que está relatando. Ortega y Gasset (1982) lo expone de la siguiente manera: cuando el historiador declara inverosímiles ciertos actos de un hombre, no es "porque en absoluto lo sean sino porque contradicen excesivamente otros datos de la vida de ese hombre, y entonces dice: esto es inverosímil en un hombre del siglo $\mathrm{X}$, aunque sería muy natural en un hombre del siglo XIX” (p. 24). Un terapeuta diría: esto es inverosímil, según lo que esta misma persona me contó la sesión pasada.

Por otra parte, tenemos las llamadas “psicoterapias narrativas”. En orden de diferenciarlas será necesario hacer un breve recorrido por la historia de la disciplina psicológica. Carlos Cornejo (2005) resalta la idea de que desde los inicios de la psicología han co-existido dos tradiciones en el conocimiento psicológico, que son distintas y discontinuas. Ambas han transitado en paralelo a lo largo de los años que lleva la psicología, tratando de hacer descripciones válidas, especialmente en el mundo académico. 
Estas concepciones son llamadas por Cornejo "cientificista" y "hermenéutica-comprensiva". Las diferencias entre estas dos maneras de entender la psicología han dado lugar a críticas mutuas de ambos enfoques, sin hacerse cargo de que ambas comprensiones dan respuesta a supuestos metateóricos distintos y discontinuos, así como a concepciones del ser humano también diferentes. Por ello, si bien ambas posturas terapéuticas se refieren a la narrativa, sus acercamientos a este concepto son distintos y no es posible compararlos sin más.

Para la concepción cientificista, la narrativa sigue el camino de la ciencia, por lo que utiliza el rigor de la metodología científica, donde los datos se analizan de tal manera que permitan mostrar regularidades, generalidades, abogando por la universalidad del conocimiento, sea en forma cualitativa o cuantitativa. En la construcción de conocimiento dentro de la concepción hermenéutica-comprensiva, escribe Cornejo (2005), “cobran importancia característicamente la historicidad de los fenómenos psíquicos, su contextualización sociocultural, y por sobre todo, la consideración de la dimensión de sentido/significado de todo acto psíquico” (p. 191).

La narrativa, siguiendo el camino de la psicología científica, ha tenido una importante evolución en estos últimos años. Entre ellos está la "visión constructivista-postracionalista", cuyo padre fue Vittorio Guidano, habiendo muchos otros seguidores de esa mirada. Uno de los representantes de este modelo es el psicoterapeuta argentino Juan Balbi (2004), que desde su comprensión sostiene que quien piensa que se "puede llegar a comprender en profundidad un problema humano solo por la forma en que el protagonista lo relata está pecando de ingenuidad" (p. 339). Para él, los cambios significativos y duraderos no son producto de cambios en los relatos. Afirma el terapeuta argentino:

La principal causa de que la psicología esté apenas intentando alcanzar el estatus de una ciencia radica, ni más ni menos, en la enorme complejidad de esta. [...] Hago votos para que los que nos dedicamos a esta difícil y apasionante tarea no nos dejemos tentar nuevamente por propuestas reduccionistas que nos alejen 
del estudio de nuestros dominios más específicos y más preciados: la mente subjetiva, la conciencia y la identidad personal (p. 339). Indudablemente, su postura sigue otro camino, distinto de la fenomenología comprensiva.

Para la concepción fenomenológica comprensiva, que prefiero llamar fenomenológica hermenéutica (Zlachevsky, 2011), lo central es el lenguaje. El lenguaje, desde esta óptica, no reside en el interior de las personas, sino que entre ellas, en tanto las palabras solo adquieren sentido y significado en el contexto de una relación particular. Nunca significan algo en sí. Leamos lo que, al respecto, escribe Ortega y Gasset (1964):

Las palabras no son palabras sino cuando son dichas por alguien a alguien. Solo así, funcionando como concreta acción, como acción viviente de un ser humano sobre otro ser humano, tienen realidad verbal. Y como los hombres entre quienes las palabras se cruzan son vidas humanas y toda vida se halla en todo instante en una determinada circunstancia o situación, es evidente que la realidad 'palabra' es inseparable de quien la dice, de a quién va dicha y de la situación en que esto acontece (p. 237).

Cada idea, cada concepto solo se concreta en el intercambio interpersonal o social con otros, en y desde el lenguaje. Los significados con los que las personas afrontan el mundo nacen siempre en y desde un contexto relacional particular. No solo se habla con palabras, sino con la manera de vestir, de pararse, de expresar, de mirar; todo eso también forma parte del lenguaje y, por tanto, de la narración. Cada una de esas formas de expresión es parte del decir. Es importante no restringir la idea de discurso solo al discurso hablado.

La mirada fenomenológica hermenéutica debe hacerse cargo de la tarea que tiene por delante, la de encontrar sus fundamentos de manera rigurosa, algo en lo cual la mirada cientificista en psicología le lleva la delantera. Como sostiene Hoyos Botero (2005), esta nueva mirada, que hoy ya no es tan nueva, se caracteriza por:

abandonar el determinismo, la causalidad lineal, la razón totalizadora, para hacerse cargo de una nueva visión atravesada 
por la construcción del mundo y de la realidad a partir de la interpretación; por el abandono de los «meta-relatos», consecuencia de no existir más una historia única, por asumir el diálogo, la comunicación social, las narraciones como nuevas formas de relación y por tener como perspectiva la complejidad, la diferencia, la multidireccionalidad y la transdisciplinariedad a partir del «fenómeno y del sentido» como elementos que reemplazan la relación científica tradicional causa-efecto y la modificación de la relación sujeto-objeto que permite una visión desfundamentadora en pos de la renuncia de lo único en favor de la multiplicidad (p. 159).

De esta manera, es posible decir que existen tres conceptos de narrativa diferentes, que llaman a comprensiones también distintas. La narrativa desde la mirada científica, la narrativa desde la mirada fenomenológico-hermenéutica, donde incluyo la narrativa sistémica, y la modalidad narrativa como modalidad del pensamiento planteada por Bruner.

Sobre la constructividad como proceso epistemológico

Otro término que lleva a equívoco, en la formación de terapeutas, es el concepto de constructivismo, construccionismo o constructividad. De hecho, la idea de constructividad, entendida como la postura que lleva al observador a hacerse cargo de sus operaciones de distinción, se ha tornado muy popular en el ámbito terapéutico. Pero esto, que podría aparecer como algo puramente positivo, para quienes nos adscribimos a esta manera de entender lleva en sí un riesgo de confusión, ya que hay muchas y muy diversas posturas constructivistas. Señala Tomás Ibáñez (2003):

En lo que denomino la galaxia construccionista, que empieza a estar muy densamente poblada [...]; encontramos al construccionismo social [...], al constructivismo filosófico [...], el constructivismo de la escuela de Palo Alto [...], el constructivismo de las terapias sistémicas, el constructivismo en la biología del conocimiento [...], el construccionismo sociológico 
[...], el constructivismo evolutivo [...]. Es muy difícil encontrar el punto de entronque entre, por ejemplo, el constructivismo en la biología del conocimiento y el construccionismo social ( $\mathrm{p}$. 164).

Me pregunto, ¿será necesario encontrar un punto de parentesco entre ellas?

Si las posturas descritas anteriormente son vistas como teorías, indudablemente es necesario acentuar las particularidades de cada una. Pero si se trata de describir el proceso de conocimiento que está a la base de ellas -entonces, incluidas en una misma postura epistemológica- se podría resaltar que lo que tienen en común es el hecho de que entienden la vida como interpretación de sí misma, es decir, resaltan el carácter hermenéutico que la vida tiene, reconociendo que toda interpretación refiere a quien interpreta.

Para poder mostrar mi propia comprensión de constructividad, acentuando el proceso epistemológico que está a la base de ello, me afirmaré en lo que entiendo es el proceso de llegar a entender a otro desde la constructividad. Humberto Maturana (1997) -reflexionando sobre cómo es que, como observadores, podemos llegar a conocer nuestro entorno y a los otros- plantea que lo que hacemos los seres humanos, como observadores, es tener la experiencia de encontrarnos "observando, conversando o actuando, y que cualquier explicación o descripción de lo que hacemos es secundaria a nuestra experiencia de encontrarnos nosotros mismos en el hacer de lo que hacemos" (p. 17). El terapeuta, estando en el proceso terapéutico, actúa haciendo terapia; no reflexiona en su hacer sino solo cuando, a posteriori, se detiene a pensar en lo que hizo; es entonces cuando busca una explicación que dé cuenta de su hacer; pero, esta explicación es otra experiencia, la experiencia de reflexionar a posteriori sobre aquello que hizo. Sostiene Maturana que "usualmente no nos damos cuenta de esto porque colapsamos la experiencia con la explicación de la experiencia, quedándonos solo con la explicación de la experiencia" (pp. 17-18), como si la explicación y lo ocurrido fueran lo mismo. Habría que tener presente, en primer lugar, el hecho de que todas las explicaciones son una segunda 
experiencia, la de explicar algo sobre una experiencia primera; soslayamos, en segundo término, el hecho de que la explicación nunca es un reflejo absolutamente fiel de la primera experiencia vivida, aquella que se quiere explicar.

El paciente llega a terapia con un relato. El terapeuta escucha ese relato, que es expresado en palabras, dichas y no dichas. El objetivo del terapeuta es entender la forma particular de significar lo que el consultante le cuenta sobre los acontecimientos vividos. Por tanto, vale la pena recordar que es un relato sobre lo vivido, no lo vivido. Como escribe Maturana (1997): "cualquier explicación o descripción de cómo ocurre la praxis del vivir en el lenguaje es operacionalmente secundaria a la praxis del vivir en el lenguaje, aun cuando la explicación y la descripción también ocurren en ella" (p. 18). Ni la explicación ni la descripción que el paciente hace reemplazan lo que ellas explican o describen. Es decir, los relatos del paciente, la forma de narrar los acontecimientos, expresados en palabras, no son sino una forma de hacer inteligible para el terapeuta la experiencia vivida, no necesariamente lo que realmente le ocurrió. En la danza de hablar (paciente) y preguntar o aseverar (terapeuta) se va creando "la realidad", que emerge en ese contexto suscitado por ambos. Esta realidad, que surge contextualizada, nunca es fija, sino que va cambiando con la conversación, siendo retocada o acentuada de determinada manera en virtud del contexto en el que las preguntas emergen, de las circunstancias de la interacción terapéutica y de las características y expectativas de ambos protagonistas del proceso: paciente y terapeuta.

Varela (2000) sostiene que cada vez que un sujeto distingue un fenómeno, lo distingue estando inserto en un contexto determinado. En este caso es el contexto de estar en terapia. Escuchemos sus palabras: "el mundo ahí afuera y lo que hago para estar en ese mundo son inseparables. El proceso los vuelve totalmente interdependientes" (p. 242). "Los fenomenólogos - dice Varela (2006)- se han explayado explicitando por qué el conocimiento se relaciona con el hecho de estar en un mundo que resulta inseparable de nuestro cuerpo, nuestro lenguaje y nuestra historia social" (p. 95). El paciente llega a consultar a un espacio terapéutico específico en 
que acepta que él es el paciente, y el terapeuta alguien que lo puede ayudar. Es en ese contexto donde adquiere sentido la conversación; es ahi y entonces, con ese terapeuta, donde el relato cobra su particular sentido. Un mismo paciente con un terapeuta diferente va a relatar su historia de otra manera. Aunque su contenido no sea totalmente distinto, los énfasis que utiliza en su relato así como la manera en que conteste a las preguntas que le hace el terapeuta, pueden hacerla ver como otra historia.

Maturana (1997) propone dos posibles caminos explicativos distintos para explicar una experiencia, que denomina el camino de la objetividad sin paréntesis - o de la objetividad trascendental- y el de la objetividad entre paréntesis - o de la objetividad constitutiva-; estas vías son las que modulan la interpretación de los hechos. La elección de uno de ambos caminos tiene consecuencias absolutamente diferentes.

En el camino interpretativo de la objetividad entre paréntesis se acepta que nuestras habilidades cognitivas constituyen un fenómeno biológico y, como tal, son un sistema que solo puede responder desde su propia estructura y conocimiento anterior. En este caso, el observador -dice Maturana (1997) - "tiene que aceptar como sus características constitutivas todas las características constitutivas de los sistemas vivientes, particularmente sus incapacidades para distinguir en la experiencia lo que en la vida diaria distinguimos como percepción e ilusión" (p. 22). Lo que percibe del mundo es de su responsabilidad, y depende de su propia estructura y conocimiento previo. Nunca se escucha en el vacío; siempre el observador tiene pre-conceptos sobre lo que distingue.

Siguiendo este argumento, es posible decir que el cerebro no es un mero recipiente donde se depositan informaciones, sino una entidad que construye la experiencia y el conocimiento, los ordena y le va dando forma dependiendo de su propio determinismo estructural. Leámoslo en palabras de Maturana (1997): "la realidad surge como una proposición explicativa de nuestra experiencia de las coherencias operacionales en nuestra vida diaria y técnica, como las vivimos en nuestra vida técnica y diaria” (p. 40).

Varela (2000) agrega que no hay un mundo que descubrir, sino que el fenómeno que se percibe surge como fruto de la actividad humana. 
Sostiene que:

La cognición está enactivamente encarnada. Enactiva es una etiqueta que utilizo aquí en un sentido literal, ya que la cognición es algo que producimos por el acto de manipular, por medio de una manipulación activa: es el principio fundacional de lo que es la mente (p. 242).

Esta afirmación implica una profunda co-implicación, una codeterminación entre lo que pareciera estar fuera y lo que pareciera estar dentro. El mundo externo y lo que hace el hombre para estar en ese mundo son inseparables. La mente no es la representación de un determinado estado de cosas; la mente es la producción constante de esta realidad coherente que constituye su mundo. La mente, para Varela (2000), "ni existe ni no existe” (p. 243). La mente emerge.

La idea de que la mente emerge, en sus propias palabras, "es una noción difícil, porque ha sido incomprendida. Utilizo el término emergencia en un sentido más bien técnico" (Varela, 2000, p. 243). Explica que cuando se observa el proceso de cognición, cada vez hay más evidencia de que se está tratando con componentes muy individuales, como neuronas o grupos de neuronas, o poblaciones de neuronas. Pero, a partir de estos elementos locales surge un proceso global, que no es ni independiente de estas interacciones ni reductibles a ellas. Es abarcador, y en ese sentido se trata de una emergencia global, de una totalidad que surge armónicamente. Escribe el biólogo: emerge un "nivel global que surge a partir de las reglas locales y que tiene un status ontológico diferente, porque trae consigo la creación de un individuo, o de una unidad cognitiva” (p. 244). Cuando vemos un perro en movimiento, por ejemplo, vemos un ser coherente completo, no una mera yuxtaposición de patas andando, de ladridos, de movimiento de la cola. Observamos una unidad integrada, más o menos armónica, que llamamos perro. Uno de los más importante avances en la ciencia en los últimos años es la convicción de que no puede haber nada que se asemeje a una mente o a una capacidad mental sin que esté totalmente encarnada en el mundo. Siempre aparece ligada a un cuerpo que es activo, que se mueve y que produce ese movimiento corporal. Desde 
ahí logra conocer el mundo, interactuando en él; por ello, el concepto de encarnado.

Ambos conceptos, el de encarnación y el de emergencia, junto con el hecho de que hay un acoplamiento estructural continuo entre los entes con los que se interactúa, es lo que constituye el aspecto central que da origen a lo que Varela (2000) llama mente. La mente no es la representación de un determinado estado de cosas; la mente es la producción constante, la percepción de la realidad para quien está observando. La cognición, escribe el biólogo, "no solo está enactivamente encarnada, sino que es enactivamente emergente, en ese sentido técnico que traté de esbozar. Puede que algunas personas se refieran a este fenómeno bajo diferentes nombres: autoorganización, complejidad, o dinámica no lineal" (p. 245). El hombre conoce porque tiene un cuerpo en el que está incluido el cerebro, y que a medida que va actuando en el mundo va conociendo ese mundo.

Tengamos presente lo que al respecto sostiene Heidegger (2007) en los Seminarios de Zollikon. Allí distingue entre el cuerpo como Körper $(K)$, el cuerpo material, y el cuerpo como Leib $(L)$, el cuerpo que somos, el cuerpo vivido. Este concepto es posible hacerlo dialogar con lo planteado por Varela (2000), en tanto sostiene que el cuerpo (L) toma parte en el ver, en el oír, tocar, etc. Pero no son los ojos los que ven, sino que soy yo la que ve. Dice Heidegger: "el ojo no ve, sino mi ojo, yo veo mediante mis ojos" (p. 136). Cuando muevo una parte de mi cuerpo, yo me muevo, es mi movimiento.

Fenomenológicamente hablando, la mente no presenta una división clara entre "la memoria por un lado, y el afecto o la visión por otro" (Varela 2000, p. 247); emergen juntos. A ojos de Varela:

uno de los descubrimientos más impactantes de los últimos años es que el afecto o la emoción está en el origen de lo que hacemos todos los días en nuestro manejo e interacción con el mundo; [...] la razón o el razonamiento vendría a ser como la cereza de la torta (p. 247).

Esta idea entra en diálogo con el existencial heideggeriano llamado disposición afectiva, encontrarse o temple de ánimo. La razón surge en 
el último estadio de la emergencia de la mente, siendo, sin duda, el afecto lo primero. Escuchemos a Varela (2000): "fundamentalmente, la mente es algo que emerge de la tonalidad afectiva, que está anclada al cuerpo. Todo el proceso ocurre en más o menos una fracción de segundo, una y otra vez" (p. 247).

Haciendo dialogar a Maturana y Varela con Ortega y Gasset y Heidegger, es posible decir que dichos pensadores aceptan la idea de que el mundo es una construcción que realiza alguien: el observador, en términos de Maturana; el cognoscente, en términos de Varela; el viviente, en términos de Ortega y Gasset, el Dasein en términos heideggerianos. Esta forma de entender se da tanto en el plano del conocimiento formal, como en el plano de la vida de cualquier hombre. El mundo que se construye no es la representación del mundo en la mente, como lo planteaba Descartes, sino que es una construcción que desde el punto de vista epistemológico lleva a entender el proceso de la constructividad.

Para el terapeuta que epistemológicamente se hace cargo de la constructividad, no hay un criterio más verdadero o preciso sobre lo que le ocurre al paciente; todos son interpretaciones. Ello, en tanto las formas de significar los acontecimientos son construcciones que forman parte de la cultura de la que terapeuta y paciente forman parte. Una terapia, dice Gergen (2005), "si es eficaz, puede -y normalmente requiere- hacer uso de múltiples formas de discurso, incluidas las de la cultura en su conjunto" (p. 92). El terapeuta tiene que tener conciencia de construcción, dice Gergen. Yo diría que tiene que estar alerta al hecho de que está constantemente co-construyendo con el paciente. En el decir del terapeuta, en el actuar o interpretar, sus emociones no están ausentes. Estas son un semáforo de alerta para el discurrir de la sesión que el terapeuta no puede dejar de ver. Estando atento a sus propias emociones e interpretaciones y por tanto a que el mundo es una construcción, no es posible, sin más, acusar a alguien de estar equivocado. La equivocación no es otra cosa que decir que no se comparten las convenciones de interpretación. El terapeuta no puede pretender con su interrogatorio "explorar qué sucede en la familia, sino generar informaciones que pueden llevar a una diferencia en los juicios 
y comprensiones que comparten los miembros de la familia” (Gergen, 2005, p. 94), de tal manera que se pueda ver a cada protagonista de otra manera. Afirma Gergen: "El mayor valor de la toma de conciencia de la construcción es que invita a limitar la realidad admitida o esencializada en los momentos en que esta resulta dolorosa o problemática” (p. 95). Quien decide lo que le es doloroso es el sistema consultante, nunca el terapeuta.

El paso que va desde "la mente en el interior de la persona» hacia el discurso que ocurre entre las personas ha abierto la puerta a muchas propuestas creativas en psicoterapia. Vale la pena mencionar, como sostiene Gergen, "el interés de las ciencias sociales por la narrativa, que consiste esencialmente en construir el selfy el mundo a través de relatos" (Gergen \& Warhuus, p. 17): metáforas, ritos, cartas, testimonios, exclamaciones públicas, entre otras.

\section{Razón narrativa y dominio de existencia}

Cuando se habla de narrativa en psicoterapia salta a la vista quiénes, hasta antes de 1990, eran reconocidos como terapeutas narrativos; se trata de los terapeutas del Dulwich Centre. Indudablemente, quienes forman parte de este centro terapéutico y de formación, localizado en Australia, son quienes marcaron una pauta en este tipo de comprensión psicoterapéutica. No obstante, incluso en el mismo centro es posible decir que no existe una única manera de entender la psicoterapia narrativa, como sostiene Alice Morgan cuando se le pregunta qué es la terapia narrativa, y contesta: "lo que se conoce como terapia narrativa abarca distintos temas y cada terapeuta se involucra también de distinta manera con estas ideas" (Morgan, 2000, p. 2). Por lo tanto, es muy difícil elaborar una única definición de terapia narrativa. En lo que sí hay acuerdo entre los distintos terapeutas del Dulwich Centre es en lo que sostiene White en relación al hecho de que "los seres humanos son seres interpretantes: que interpretamos activamente nuestra experiencia a medida que vamos viviendo nuestra vida” (2002, p. 17). También es posible encontrar acuerdo en lo que Russel y Carey resumen en la frase "la persona no es el problema, el problema es 
el problema" (2004, p. 3). Esta forma de entender lo narrativo ha llevado a un gran desarrollo de estas prácticas, que no se reducen solo a la psicoterapia, sino que incluyen prácticas sociales de trabajo con distintos grupos. Ello no solo en Australia, sino en distintas partes del mundo, ya que han sido muy eficientes para ofrecer miradas alternativas al dolor en distintos tipos de personas, grupos o colectividades humanas.

Bertrando (Bertrando \& Tofanetti, 2004) afirma que después del año 1990 la definición de terapia centrada en las narrativas empieza a extenderse a otros tipos de terapia, y se comienza a "sustituir, el nombre de «terapia sistémica»" (p. 284). Ello no resulta difícil de entender en tanto, como escribí en 1997:

Para poder contar nuestra vida, dándole sentido al relato, inevitablemente se requiere un razonar sistémico, se requiere poder mostrar las relaciones entre los personajes que formaban parte de la historia a contar. Quién es quién, qué rol juega en la historia, dónde transcurren los acontecimientos que se están relatando, qué hizo él o ella cuando yo hice, qué hice yo cuando él o ella hizo esto o aquello. Como en una pieza de teatro, cada personaje ejecuta un papel y sigue un guión del que no es consciente pero que sabe interpretar a la perfección. Los acontecimientos que van transcurriendo, van teniendo sentido o significación en el argumento total de la historia (Zlachevsky, 2003, p. 49).

¿Qué proceso está a la base de esta comprensión de narrativa?

Resulta interesante recurrir a los filósofos para responder esta pregunta. De hecho, pareciera que no es posible hablar de narrativa sin hacer referencia a la razón narrativa que a su vez se sustenta en la aceptación de la razón histórica. Ante todo, la razón no es, dice Ortega y Gasset (1966), la razón lógica, sino la razón histórica. El hombre es lo que le ha pasado; por ello, todo lo hecho, todo el pasado lo lleva a su espalda. El hombre de hoy es el resultado de los hombres anteriores; por eso dice Ortega y Gasset que "el hombre no tiene naturaleza, sino que tiene... historia" (p. 51). 
El hombre vive en un determinado momento, en determinado tiempo, que es una época histórica. Escuchémoslo en palabras de Ortega y Gasset (1997): "literalmente hablando «tiempo no es, en última verdad, el que mide los relojes», sino que tiempo es tarea, misión, innovación" (p. 84). La tarea de nuestro tiempo es dirigir innovadoramente la mirada al futuro, pero sustentando sus propuestas en su historia, su pasado. En cada época hay, hubo y habrá una forma de vida que dura cierto tiempo. En dicha época y tiempo coexisten varias generaciones. Existen contemporáneos: los que viven en el mismo tiempo; y existen coetáneos: los que tienen la misma edad histórica. Esta diferencia es la que permite la innovación.

Vivir es vivir en sociedad, por lo que es posible decir, con Marías (1961):

En cada acto humano gravita la historia entera. Hay que apelar, pues, a la historia en su integridad, qué nos ha pasado a cada uno de nosotros: la forma concreta de la razón vital es la razón histórica. Pero adviértase que esta razón histórica y vital no es una forma particular de la razón, sino más bien al contrario: la razón sin más y sin adjetivos, la razón en su sentido pleno, frente a las particularizaciones y simplificaciones abstractas de la razón, que se suelen confundir con ella, porque son las únicas de que hasta ahora se ha hecho teoría (p. 79).

Se está refiriendo Marías (1961) a la razón de las ciencias físicomatemáticas, a la de la geometría, al razonamiento formal. Pero para vivir ese razonamiento es insuficiente. Para vivir y relatar nuestra vida se requiere un razonar distinto, a saber, "una razón narrativa" (p. 80). Es ese tipo de razonar el que se hace presente cuando un sistema consultante responde a la pregunta ¿qué lo trae a consultar?

La razón narrativa permite la conectividad entre los personajes que forman parte de la historia a contar, de quienes comparten una experiencia. Dice Bateson (1990): "sea cual fuere el significado de la palabra historia, [...], el pensar en términos de historia no aísla a los seres humanos del resto de los entes" (p. 12). Hablar en términos de historia y de narración, permite entender, afirma el antropólogo, "la noción de contexto, de 
pauta a lo largo del tiempo" (p. 13); aparece pues, en su perspectiva, como algo distinto y de relevancia "una razón narrativa" (Marías, 1961, p. 85).

La narración es la forma "de presentación o patentización de la vida humana en su articulación interna, en su conexión viviente" (Marías, 1961, p. 80). Para que el relato de alguien tenga sentido es necesario que estén presentes los ingredientes que componen la vida de la persona. El puro relato, continúa Marías (1969):

cuando se limita a narrar, con la mayor desnudez posible, da una descripción insuperablemente eficaz de la circunstancia o mundo, porque alude a aquellos elementos que están realmente actuando en el hacer referido y recoge la verdadera figura de un «mundo» humano (p. 238).

Muestra el cómo acontece la acción y cómo intervienen los actores que forman parte del guión. Si los actores cambian, cambia también la narración. Por ello es posible decir que no se trata de una sola narrativa, sino que aparecen distintas narrativas dependiendo de los distintos dominios de existencia en los que la persona se desenvuelve. Recuerdo una persona que consultó por un problema que llamó timidez; no obstante, se trataba de un alto ejecutivo que tenía a su cargo el departamento de adquisiciones de una gran empresa. Su llamada timidez no se hacía presente en las negociaciones laborales, sino solamente en sus relaciones con el sexo opuesto; en especial, con una mujer por la cual el paciente sentía un afecto especial.

Las personas sentimos y nos comportamos de diferente manera en distintas situaciones y con diferentes personas. En el libro La objetividad, un argumento para obligar, Maturana se refiere a ello. Afirma que tenemos configuraciones operacionales distintas según con quién estemos, cómo nos entendamos a nosotros mismos en ese dominio y según los distintos actores que configuran dicho dominio. Lo llama dominio de realidad o dominio de existencia. Señala Maturana que "cada configuración de operaciones de distinciones que el observador ejecuta, especifica un dominio de realidad como un dominio de coherencias operacionales de su praxis del vivir en la cual él o ella trae a la mano un tipo particular de comportamiento" (p. 27). El cuento que se nos cuenta o nos contamos sobre quiénes 
somos surge de la danza de intercambios comunicacionales que ocurre en los distintos dominios de existencia en los que nos desenvolvemos. En el año 1998 escribí:

Las personas estamos insertas en una forma de entender el mundo, una forma que nos fue enseńada y que aprendimos. Este aprendizaje se logra a través de la interacción con quienes 'convivimos' directa e indirectamente. Es con otros con quienes aprendimos a dar un significado a nuestras distinciones. Esta forma particular de significar el mundo está relacionada, no solo con quienes convivimos en interacción directa, sino que está determinada por la propuesta social en la que nos tocó desarrollarnos (p. 18).

De tal manera que las redes de significado compartido están limitadas a los actores que participan en dichas redes y a la propuesta social que determina qué es posible de esperar en esas situaciones en las que participamos. Por otra parte, incide también la generación que nos sirve de referencia. Por ejemplo, a las personas mayores de sesenta años nos cuesta entender lo que la juventud de hoy define como "un andante" en una determinada relación de pareja. Escribí en 1998:

En cada uno de estos sistemas sociales, nos comportamos de forma distinta y esperamos que los otros se comporten también de una cierta manera que, por supuesto, también es diferente de otros sistemas sociales. Por ejemplo, yo me comporto distinto con mis nietos, hijos, mi pareja, mis alumnos o mis amigos y ellos, a su vez, se comportan diferente conmigo. Es decir, en cada dominio social o dominio de existencia la narrativa que me constituye es distinta. Podríamos decir que vivimos tantas tramas narrativas como sistemas sociales o dominios de existencia en los que participamos (Zlachevsky, p. 20).

En esos dominios de existencia somos reconocidos de determinada manera por los otros. Ello en tanto, como sostiene Taylor (1993), "el reconocimiento debido no solo es una cortesía que debemos a los demás: es una necesidad humana vital" (p. 45). Cada dominio lleva a que los participantes en él tengan cierta forma de conversar y explicarse la vida y 
sus relaciones, narrándose unos a otros; dice Maturana (1997) que "cada dominio de realidad constituye un dominio de explicaciones de la praxis del vivir del observador" (p. 25).

Si bien todos los dominios de realidad son diferentes, "en término de las coherencias operacionales que los constituyen" (Maturana, 1997, p. 25), ellos son todos igualmente válidos como dominios de existencia. Todo lo que un observador distingue, incluyendo al observador en sí mismo, se distingue desde ese dominio existencial. Más aún, dice el biólogo:

Hay tantos dominios de realidad legítimos distintos como dominios de explicaciones que un observador puede traer a la mano a través de las coherencias operacionales de su praxis del vivir, y todo lo que un observador dice, pertenece a uno de ellos. Debido a esto, toda afirmación que un observador hace es válida en algún dominio de realidad, y ninguno es intrínsecamente falso (p. 28).

Por tanto, el terapeuta debe ser capaz de interpretar desde qué dominio de existencia el consultante le está hablando de que algo lo incomoda, y quiénes son los personajes que forman parte de ese dominio explicativo; y no debe olvidar que está en el dominio de existencia del "proceso terapéutico».

Lo interesante de esta propuesta es que el terapeuta que acepta esta mirada, sabe que:

cada dominio de explicaciones constituye un dominio de acciones (y de afirmaciones como acciones en un dominio de descripciones) que un observador considera en sus reflexiones como acciones legítimas para un dominio particular de la praxis del vivir porque ellas están respaldadas por las explicaciones que él o ella acepta en ese dominio (Maturana, 1997, p. 28).

De esta manera, no existe una manera única de entender las circunstancias, ni tampoco una sola manera de narrarla.

El terapeuta no solo debe saber en qué dominio de existencia está inserto el relato de lo que el paciente le cuenta, sino que debe lograr ver qué le pasa a él en ese dominio existencial. Por ejemplo, si un psicotera- 
peuta se está separando de su pareja y su paciente le cuenta que quiere separarse, debe saber muy bien si está o no en condiciones de trabajar con esa persona, ya que sus propias emociones le pueden jugar malas pasadas en el trabajo terapéutico. La pregunta que debería hacerse el terapeuta es: ¿qué veo yo, como terapeuta? ¿Qué les (o le) está pasando hoy a estas personas que los (o lo) tiene atrapados en el sufrimiento? ¿En qué dominio de existencia está inserto el dolor? ¿Puedo yo trabajar con ellos? ¿Hasta dónde me puede perturbar mi propia deriva personal?

La orientación final de la terapia es de co-construir en el proceso terapéutico una narrativa nueva, que emerja desde las propias creencias del cliente, que elimine su sufrimiento o le permita abordar su problema de manera diferente. Como sostienen Rosenbaum y Dickman (1995), “cuando la experiencia es discordante con nuestros conceptos de lo que «debiera» ser o es, nuestros intentos de mantener la auto-imagen pueden resultar en síntomas psicológicos” (p. 8), o en experiencias que lleven a dudar de lo que las personas quieren hacer.

Acercarse a entender la psicoterapia narrativa, desde una óptica fenomenológica hermenéutica, es posible, si seguimos el pensamiento de los filósofos fenomenólogos o de pensadores cercanos a la fenomenología en algunos aspectos relevantes. Entre ellos se encuentra Martin Buber (2006), para quien lo central en la construcción de un fenómeno es la dupla yo-tú, donde el tú es reconocido como el otro con quien me contacto, siendo esta una vinculación natural. Es lo que ocurre en psicoterapia cuando quien consulta dice haber sentido una vinculación especial con su terapeuta que, por lo general, se refleja en las palabras "me sentí escuchado". Leamos las palabras de Buber: "el tú me encuentra. Pero yo entro en una relación directa con él. De modo que la relación es ser elegido y elegir, pasión y acción a la vez" (p. 18). Es en la relación yo-tú donde emerge el diálogo y en donde cada persona confirma a la otra como valor único. Buber la opone a la relación yo-eso y afirma que “[...] el yo separado está reducido de la plenitud sustancial a la puntualidad funcional de un sujeto que experimenta y que usa cosas [...]" (p. 33); entonces, el ser humano que devino en yoeso, mira a través de la lupa objetivadora. Es lo que ocurre en psicoterapia 
cuando se usan clasificaciones o diagnósticos y se rompe la intimidad del encuentro humano cara a cara, donde la confianza es el contexto que le da sentido a la sesión.

Para Buber (2006) "el lenguaje no está en el hombre, sino que es el hombre el que está en el lenguaje [...] el espíritu no está en el yo, sino que en el yo y el tứ (p. 40), que configuran una unidad. La relación con el Tú, desde esa óptica es inmediata. Entre el Yo y el Tú no media ningún sistema conceptual, ninguna presencia y ninguna fantasía. En ese encuentro humano, íntimo, sincero, cara a cara, los ojos traslucen el emocionar sin restricciones, el otro se siente seguro de relatar lo que le acontece, se siente con la libertad de que sabe será "bien" interpretado. El terapeuta a su vez se siente con la libertad de preguntar, de conversar, sabiendo que sus preguntas y aseveraciones serán bien entendidas. Cuando estamos "en el mundo del tú, no hay continuidad en el espacio y el tiempo" (p. 37), hay solo presencia actual, presente. El aquí y ahora se impone naturalmente. Es entonces cuando

el silencio ante el tú, el silencio de todas las lenguas, la callada espera en la palabra informe, indiferenciada, pre-lingüística, deja en libertad al tú y permanece con él en ese estado de reserva en el que el espíritu no se manifiesta sino que es (p. 41).

El lenguaje, continúa Buber, "no está en el hombre, sino que es el hombre que está en el lenguaje y habla desde él, así ocurre con toda palabra” (p. 41). Esta afirmación recuerda a Heidegger y la idea de que el lenguaje es la morada del hombre, es decir, es una manifestación ontológica (Zlachevsky, 2011). Escribe Buber que "el ser humano habla en diversas lenguas: la lengua verbal, la del arte, la de la acción, mas el espíritu es uno, es una respuesta al tú que emerge del misterio y nos habla desde el misterio" (p. 41). En este caso se trata del misterio presente en la relación terapéutica, que nos lleva a sonreír cuando un sistema consultante nos da las gracias por lo conversado.

Desde la mirada fenomenológica hermenéutica, la comprensión que la ciencia tiene del hombre no tiene un lugar absoluto, es otro acercamiento al paciente. No es mejor ni peor, solo distinto, respondiendo a 
imágenes del ser humano también distintas, enfrentando las incógnitas de lo humano también de manera diferente.

\section{Discusión}

Este artículo pretende poner de manifiesto dos procesos. Uno que está a la base de las posturas constructivistas y construccionistas (nivel epistemológico), y otro que dé cuenta de la forma de razonar que se encuentra a la base de las llamadas psicoterapias narrativas (operar terapéutico).

Para lo primero se propone buscar una postura epistemológica común al constructivismo y al construccionismo social. Se hace resaltar que lo que tienen en común ambas comprensiones es el hecho de que entienden la vida como interpretación de sí misma, es decir, destacan el carácter hermenéutico que la vida intrínsecamente tiene. Reconocen que toda interpretación describe, en última instancia, a quien interpreta. A este proceso se le llamó constructividad y estaría sustentado en los planteamientos de Maturana y Varela, entre otros. Esta idea de constructividad, entendida como la postura que lleva al observador a hacerse cargo de sus operaciones de distinción, sería el posible parentesco entre los distintos constructivismos.

En relación a la psicoterapia narrativa, dado que este concepto también lleva a equívocos, la autora propone recurrir a entender el proceso que está a la base de la comprensión narrativa. Este proceso es posible de encontrar en la razón narrativa, que se diferencia de la razón lógica y la fundamenta. Para dar cuenta de ello recurre a los filósofos Ortega y Gasset y Marías, equiparando la biografía de los consultantes con la historia de los pueblos a la que aluden esos filósofos.

Argumenta que la razón narrativa permite establecer claramente la conectividad entre los personajes que forman parte de la historia a contar y de quienes comparten una experiencia. Ello, en tanto hablar en términos de historia y de narración permite entender las nociones de contexto, de pauta a lo largo del tiempo y de conectividad entre los personajes, básicos para poder ejercer como terapeuta narrativo. Desde esta forma de 
entender, resalta la relación yo-tú, acuñada por Buber como una forma de comunicación presente en la psicoterapia que confirma al otro como un ser único e irrepetible.

El artículo pretende mostrar una línea de reflexión o una invitación a pensar en lo planteado. En ningún caso puede verse como algo acabado, ya que ello es imposible en el marco de un artículo de esta naturaleza. Indudablemente, este texto debería ser leído como una propuesta que, a ojos de la autora, bien vale la pena discutir y enriquecer.

\section{Referencias}

Balbi, J. (2004). La mente narrativa. Buenos Aires: Paidós.

Bateson, G. (1990). Espiritu y naturaleza. Buenos Aires: Amorrortu.

Bertrando, P. \& Toffanetti, D. (2004). Historia de la terapia Familiar. Las ideas y los personajes. Barcelona: Paidos Ibérica.

Bruner, J. (1998). Realidad mental y mundos posibles. Barcelona: Gedisa.

Buber, M. (2006). Yo y Tú y otros ensayos. Buenos Aires: Lilmod.

Cornejo, C. (2005). Las dos culturas de/en la psicología. Revista de Psicología, 14(2), 189-208.

Gergen, K. (2005). Construir la realidad. Barcelona: Paidós.

Gergen, K. \& Warhuus, L. (2001). La terapia como una construcción social dimensiones, deliberaciones y divergencias. Sistemas Familiares, 1, 11-27.

Heidegger, M. (1989). Serenidad. Barcelona: Ediciones del Serbal.

Heidegger, M. (2007). Seminarios de Zollikon. Protocolos. Diálogos. Cartas. Edición de Medard Boss. Morelia, Michoacán, México: Red Utopía A.C., Jitanjáfora.

Hoyos Botero, C. (2005) Aproximación a una psicología postmoderna: una reflexión epistemológica. Informes psicológicos, 7, 137-175. Recuperado de http://www.google.cl/url?sa=t\&rct=j\&q=\&esrc=s\&sou $\mathrm{rce}=$ web $\& \mathrm{~cd}=1 \& \mathrm{cad}=\mathrm{rja} \& \mathrm{ved}=0 \mathrm{CCQQFjAA} \& \mathrm{url}=\mathrm{http} \% 3 \mathrm{~A} \% 2 \mathrm{~F}$ \%2Fwww.upb.edu.co\%2Fpls\%2Fportal\%2Furl\%2FITEM\%2F64 28176074A74A08E0440003BA8AE9C9\&ei=WEpFUNaoEqWn6 AGi6IDgDw\&usg=AFQjCNGp-OEhQEimttp_ral0r7l_7ldZ8w\& sig2=rOzMTspmcNMsOOxLerQmbA

Ibáñez, T. (2003). La construcción social del socioconstruccionismo: retrospectiva y perspectivas. Politica y sociedad, 40, 1, 155-160. 
Marías, J. (1961). El método histórico de las generaciones. Madrid: Revista de Occidente.

Marías, J. (1969). Introducción a la filosofía. Madrid: Revista de Occidente.

Maturana, H. (1997). La objetividad, un argumento para obligar. Santiago de Chile: Dolmen.

Molinari, J. (2003). Psicología clínica en la posmodernidad: perspectivas desde el construccionismo social. Psykhe, 12(1), 3-15.

Morgan, A. (2000). What is narrative therapy? Adelaida: Dulrich Centre.

Ortega y Gasset, J. (1966). Historia como sistema. Madrid: Revista de Occidente.

Ortega y Gasset, J. (1981). El hombre y la gente. Madrid: Revista de Occidente en Alianza Editorial.

Ortega y Gasset, J. (1982). En torno a Galileo. Madrid: Revista de Occidente en Alianza Editorial.

Ortega y Gasset, J. (1997). ¿Qué es filosofía? México: Porrúa.

Rosenbaum, R. \& Dyckman, J. (1995). Integrando el sí-mismo (self) y el sistema: ¿¿Una intersección vacía? Family Process, 34, 21-44.

Russel, S. \& Carey, M. (2004) Narrative Therapy. Adelaida: Dulwich Centre Publications.

Taylor, Ch. (1993). El multiculturalismo y La politica del reconocimiento. México: F.C.E.

Varela, F. (2000). El fenómeno de la vida. Santiago de Chile: Dolmen.

Varela, F. (2006). Conocer. Barcelona: Gedisa.

White, M. (2002). Reescribir la vida. Barcelona: Gedisa.

Zlachevsky, A. M. (1998). ¿Es posible ser coherente? Terapia Psicológica, 29, 17-23.

Zlachevsky, A. M. (2003). Psicoterapia sistémica centrada en narrativas: una aproximación. Revista universitaria Limite (Universidad de Tarapacá, Arica, Chile) 10, 47-64. Recuperado de: http://dialnet.unirioja.es/servlet/listaarticulos?tipo_busqueda=EJEMPLAR\&revista_ busqueda $=7797 \&$ clave_busqueda $=137203$

Zlachevsky, A. M. (2011). Psicoterapia Conversacional: Una mirada desde Heidegger y Ortega: Aportes a la fundamentación filosófica de la praxis psicoterapéutica. Saarbrücken: Editorial Académica Española.

Fecha de recepción: 13 de enero de 2012.

Fecha de aceptación: 19 de noviembre de 2012. 